\title{
Characteristics of energy intake under-reporting in French adults
}

\author{
Isabelle Berta Vanrullen ${ }^{1 *}$, Jean-Luc Volatier ${ }^{2}$, Aurélie Bertaut ${ }^{3}$, Ariane Dufour ${ }^{2}$ and \\ Jean Dallongeville ${ }^{4}$ \\ ${ }^{1}$ Epidemiological Surveillance Unit (Survepi), French Agency for Food, Environmental and Occupational Health and Safety \\ (Anses), 27-31 Avenue du Général Leclerc, Maisons-Alfort Cedex 94701, France \\ ${ }^{2}$ Observatory of Food Consumption Unit (Nutritional Epidemiology), French Agency for Food, Environmental and \\ Occupational Health and Safety (Anses), 27-31 Avenue du Général Leclerc, Maisons-Alfort Cedex 94701, France \\ ${ }^{3}$ Breast Cancer Registry of Cote d'Or, Centre Georges François Leclerc, 1 Rue du Professeur Marion, Dijon 2100o, France \\ ${ }^{4}$ Public Health and Epidemiology Department, INSERM 744, Institut Pasteur de Lille, Lille, France
}

(Submitted 6 September 2012 - Final revision received 16 October 2013 - Accepted 16 October 2013 - First published online 13 December 2013)

\begin{abstract}
Energy intake under-reporting (UR) is a concern in nutritional epidemiological studies, as it may distort the relationships between dietary habits and health. Although UR is known to be associated with certain characteristics, few studies have investigated them in France. Therefore, the goal of the present study was to assess the prevalence and characteristics of UR in French adults. UR was defined according to Goldberg's classification. A sample of 1567 adults was drawn from the nationally representative French dietary survey (Individuelle Nationale des Consommations Alimentaires 2 2006-7). Food intake ( $7 \mathrm{~d}$ record), dietary habits, socio-economic status, region of residence, sedentary behaviour and weight perception variables were assessed. Multivariate logistic regression was used to investigate the associations between UR and a number of covariates. The overall prevalence of UR was $22.5 \%$, similar in men and women. In both sexes, UR was positively associated with overweight and protein intake and inversely associated with age. In women, UR was associated with eating lunch in the office, poor perception of diet quality and sedentary behaviour and was inversely associated with educational level, residence in the Paris region, cereal product intake and eating lunch in a friend's or family member's home. In men, UR was positively associated with a history of slimming and inversely associated with dairy product intake and eating lunch at a staff canteen. In conclusion, UR is prevalent in French adults and is associated with several different characteristics. It is important to take account of UR when investigating diet-disease associations in adults.
\end{abstract}

Key words: Dietary surveys: Energy intake: Under-reporting

Accurate food intake measurement is a major challenge in nutritional epidemiological studies, as this parameter affects the validity of associations between dietary habits and health outcomes $^{(1-5)}$. Energy intake (EI) under-reporting (UR) is a common source of bias in dietary surveys ${ }^{(6-10)}$; for instance, Black et $a l .{ }^{(7)}$ found that in surveys employing diet records, diet recall and diet history, UR, respectively, affected 64, 88 and $25 \%$ of the studied samples.

Methods used for the validation of EI are based on the principle that EI is equal to energy expenditure (EE) when body weight is stable. EE can be estimated from the BMR and the energy needed for a given physical activity level (PAL). BMR itself can be predicted from the weight and height of subjects by applying one of the several published equations $^{(11-16)}$, the choice of which can influence the classification of subjects as under-reporters. Goldberg and Black's ${ }^{(6,7,9)}$ method for identifying under-reporters is based on the comparison of the ratio of the reported EI to the BMR with the PAL. To determine whether a given mean or individual value of reported EI:BMR is acceptable, the ratio has to fall within the $95 \%$ confidence limit of a value defined by the Goldberg and Black equation; values below or above this cut-off are considered to correspond to under-reporters or over-reporters, respectively.

A better understanding of the factors that affect EI reporting is important for improving dietary assessment and perhaps even nutritional survey design. Previous investigations of the characteristics of under-reporters ${ }^{(17-31)}$ have shown that women ${ }^{(18,25-28)}$, the elderly ${ }^{(18,21,26-28)}$ and overweight individuals ${ }^{(18,21,25,27,30,31)}$ are more likely to

Abbreviations: EE, energy expenditure; EI, energy intake; INCA2, Individuelle Nationale des Consommations Alimentaires 2; PAL, physical activity level; UR, under-reporting.

*Corresponding author: I. Berta Vanrullen, fax +33149773892, email isabelle.berta-vanrullen@anses.fr 
under-report their EI. In contrast, data on the effects of several other factors (such as food habits, moderate-tovigorous physical activity and sedentary behaviour ${ }^{(29,32)}$, socio-economic factors ${ }^{(18,21,25,27,33)}$ and body-image perception $^{(25,27,28)}$ ) are scarce or inconsistent.

The reasons for UR may differ from one country to another, as nutritional habits are partly determined by cultural and geographical factors ${ }^{(34,35)}$. In France, previous studies have estimated UR among the nationally representative Individuelle Nationale des Consommations Alimentaires 2 (INCA2) dietary survey participants and have characterised UR in specific populations of children ${ }^{(29)}$ and adults ${ }^{(17,20,24)}$. On the basis of the INCA2 survey, the primary objective of the present study was to identify factors associated with energy UR in adults, including several that have not been well characterised to date (geographical area of residence, sedentary behaviour and the place where lunch is eaten). The secondary objective was to assess the effect of estimating BMR with two different equations - namely the Oxford ${ }^{(16)}$ and the Schofield equations $^{(11)}$ - on the prevalence of UR and the characteristics of under-reporters (see Supplementary Tables 1 and 2, available online).

\section{Study design and subjects}

The French INCA2 cross-sectional survey was carried out between December 2005 and May 2007 by the French Food Safety Agency (Agence française de sécurité sanitaire des aliments) ${ }^{(36)}$. The survey was primarily designed to assess food intake patterns. A complex sampling design was used to obtain a nationally representative sample of French people ${ }^{(36-38)}$. Briefly, two independent, random samples (adults aged between 18 and 79 years and children aged between 3 and 17 years) were obtained using a multistage cluster sampling technique. The sampling frame was based on the national census published by the French National Institute of Statistics and Economic Studies (Institut National de la Statistique et des Études Économiques). First, 181 primary geographical units (stratified by the region of residence and the number of inhabitants in the urban area) were randomly selected with probability proportional to size. Second, households were randomly drawn from each primary unit, and two independent sampling frames were set up: the first was restricted to households including at least one child and the second included households regardless of the presence of children. Lastly, either a child or an adult was randomly selected from each household. The participation rate for subjects aged 18 years or above was $63 \%$, which yielded a sample of 2624 adults (women: $58 \cdot 6 \%$ ).

The INCA2 protocol was approved by the French Data Protection Authority (Commission Nationale Informatique et Liberté) and the French National Council for Statistical Information (Conseil National de l'Information Statistique), especially the Committee of Label for Statistical Surveys (Comité du Label des Enquêtes Statistiques). Verbal informed consent was obtained from all the subjects. Verbal consent was witnessed and formally recorded.

\section{Measurements}

Food intake was assessed using a $7 \mathrm{~d}$, open-ended, estimated food diary. Data on behavioural, demographic and socioeconomic variables were collected through self-questionnaires and face-to-face questionnaires. The region of residence was recorded during a face-to-face interview. A trained, certified investigator handed over the food diary and the self-questionnaire at each respondent's home and spent 45-60 min explaining how to fill them out. The investigator returned to the respondents' home after the weeklong survey and checked the accuracy of the information recorded in the documents.

Age and weight status. Age (in years) was coded as a qualitative variable according to the categories in the Schofield and Oxford equations; this resulted in three groups: 18-30; 30-60; >60. Anthropometric data were collected during home visits by trained interviewers. Weight was measured in light clothes and without shoes to the nearest $0 \cdot 1 \mathrm{~kg}$ using electronic scales (Teraillon). Height was measured to the nearest centimetre (in the standing position and without shoes) with a portable gauge. Based on the guidelines of World Health Organization ${ }^{(39)}$, BMI was categorised into thin (BMI $<18.5 \mathrm{~kg} / \mathrm{m}^{2}$ ), normal (BMI $18.6-24.9 \mathrm{~kg} / \mathrm{m}^{2}$ ), overweight (BMI $25 \cdot 0-29 \cdot 9 \mathrm{~kg} / \mathrm{m}^{2}$ ) and obese (BMI $\geq 30 \mathrm{~kg} / \mathrm{m}^{2}$ ).

Geographical area of residence. The participants were classified according to their region of residence into a threeclass variable: 'northern France' (Champagne, Picardie, Haute-Normandie, Centre, Basse-Normandie, Bourgogne, Nord, Lorraine, Alsace, Franche-comté, Pays de Loire and Bretagne); 'southern France' (Poitou Charente, Aquitaine, Midi-Pyrénées, Limousin, Rhône-Alpes, Auvergne, Languedoc and Provence côte d'azur); 'Paris region'. The latter class covered the 'Ile de France' administrative region of France.

Dietary intake data. Dietary intake was recorded in the $7 \mathrm{~d}$ food diaries. In the diaries, each day was divided into three main meal (i.e. breakfast, lunch and dinner) periods and three between-meal periods. The participants estimated portion sizes using the validated Supplémentation en Vitamines et Minéraux Anti-oxydants (SU-VI-MAX) ${ }^{(40)}$ photographic booklet. If they preferred, the participants could also choose to express the amounts eaten in grams using their own household measures and scales. Dietary intake was evaluated using the food composition tables from the French Data Centre on Food Quality (Centre d'information sur la qualité des aliments $^{(41,42)}$. The average daily $\mathrm{EI}$ (in $\mathrm{MJ} / \mathrm{d}$ ) and the percentage of contribution of carbohydrates, fat and proteins to total EI were assessed. The contribution of nutrients to EI was addressed as categorical variables based on the tertiles of their distribution, leading to three levels ('low', 'intermediate' and 'high'). The frequencies of consumption of (1) cereal products, (2) meat, poultry, fish and eggs and (3) dairy products (milk, milk products and cheese) were also assessed from the $7 \mathrm{~d}$ food diaries and coded into the following three categories: 'every day'; 'every week'; 'don't know'.

Food habits and concerns. The possible places at which lunch was eaten were as follows: 'at home'; 'staff canteen'; 'at work but not in the canteen'; 'at a friend's or family member's home'; 'at a fast-food outlet or restaurant'. Whenever 
food or drink was consumed, the participants had to mention whether this was taken as a meal or as a snack. 'Snacking frequency' was defined as episodes of eating between the main meals and was coded as 'regularly' ( $\geq$ once a day), 'occasionally or never' ( $\geq$ once a week or never) or 'don't know'. The usual frequency of fast-food consumption was coded as 'regularly' ( $\geq$ once a week), 'occasionally or never' ( $\geq$ once a year or never) or 'don't know'. The usual frequency of purchasing food from a vending machine was coded as 'regularly' ( $\geq$ once a day), 'occasionally or never' ( $\geq$ once a week or never) or 'don't know'.

Socio-economic status. Occupational status was divided into four categories: 'farmers or junior managers'; 'workers'; 'senior managers'; 'homemakers or students'. Educational level was divided into three categories: 'primary school'; 'secondary school'; 'university'. Household living standards were addressed as follows: 'having gone away on holiday for more than $4 \mathrm{~d}$ within the last 3 months' (yes/no); 'perception of financial situation' ('good', 'moderate' or 'poor'); 'financial access to desired food products' ('good', 'moderate' or 'poor').

Food and weight concerns. The respondents were also asked about their food concerns: the variable 'perception of diet quality' was divided into three categories ('good', 'not good' and 'don't know').

The participants were asked to state whether they were on a restrictive diet at the time of the survey ('yes'/'no') and whether they had been on a weight-loss diet during some time in the past and how they perceived their current weight ('normal', 'overweight', 'too thin' or 'don't know').

Sedentary behaviour and physical activity. Sedentary behaviour was measured in $\mathrm{min} / \mathrm{d}$, as described elsewhere ${ }^{(29)}$. Briefly, a global index labelled 'total screen time' (based on the time spent watching television and the time spent in front of a computer or playing video games) was divided into tertiles of sedentary behaviour ('high sedentariness', 'moderate sedentariness' and 'low sedentariness'). The moderate-to-vigorous intensity physical activity of each participant was assessed using the validated International Physical Activity Questionnaire ${ }^{(43)}$ and treated as a qualitative variable ('high', 'moderate' and 'low').

Classification of under-reporters, normal reporters and over-reporters. UR and over-reporting were investigated using Goldberg's CUT-OFF 2 criterion ${ }^{(6,9)}$. A hypothesis of a moderately inactive lifestyle was set for the entire sample, leading to a PAL value of $1.55^{(44)}$. The BMR was estimated using the Schofield ${ }^{(11)}$ and Oxford equations ${ }^{(16)}$ for age and sex categories. Since the BMR values obtained with each of these equations were highly correlated $\left(R^{2} 0 \cdot 97\right)$, the results obtained using the Oxford equation were considered in the primary analysis. Goldberg's CUT-OFF 2 was established as follows:

$$
\begin{aligned}
\mathrm{PAL} & \times \exp \left(\mathrm{SD}_{\min } \times \frac{(S / 100)}{\sqrt{n}}\right)<\frac{r \mathrm{EI}}{\mathrm{BMR}}<\mathrm{PAL} \\
\times & \exp \left(\mathrm{SD}_{\max } \times \frac{(S / 100)}{\sqrt{n}}\right)
\end{aligned}
$$

where $n$ is equal to 1 (for data on the individual level), the standard deviation $\left(\mathrm{SD}_{\min }\right)$ is \pm 1.96 (corresponding to the lower and upper boundaries of the $95 \% \mathrm{CI}$ ) and $S$ is calculated as follows:

$$
S=\sqrt{\left(\frac{\mathrm{CV}_{\mathrm{wEI}^{2}}}{d}+\mathrm{CV}_{\mathrm{wBMR}^{2}}+\mathrm{CV}_{\mathrm{tP}^{2}}\right)},
$$

where $d$ is the number of recording days (seven in most cases), $\mathrm{CV}_{\mathrm{wEI}}$ is the within-subject variation in $\mathrm{EI}(23 \%), \mathrm{CV}_{\mathrm{wBMR}}$ is the precision of the estimated BMR relative to the measured BMR (8.5\%) and $\mathrm{CV}_{\mathrm{tP}}$ is the between-subject variation in PAL (15\%). The participants were classified by creating dichotomous outcomes ( $1=$ under-reporters; $0=$ not under-reporters $)$ or $(1=$ over-reporters; $0=$ not over-reporters $)$.

\section{Statistical analyses}

All the analyses were carried out using the SAS software (version 9.3; SAS Institute Inc.). Data were weighted for unequal sampling probabilities: a complex unproportional three-degree design with stratification was applied to the sampled subjects included in the survey. The primary units were constituted of geographical areas, and stratification was applied to the degree of urbanisation. The secondary units were constituted of housing, with no stratification on rural area and stratification on urban area. The third degree was constituted of subjects inside housing. According to the INCA2 adult population ( $n$ 2624), 234 men (21\%) and 577 women (37\%) were on a weight-loss diet and $28(1.8 \%)$ women were pregnant at the time of data collection. Anthropometric data (weight and/or height) were missing for $9 \%$ of the participants ( $n$ 254). Therefore, all these subjects were excluded from the analysis, to comply with Goldberg's steady-state criterion and to improve the accuracy of the data ${ }^{(6,9)}$. Some of the excluded participants were characterised by more than one of these criteria. In this step, over-reporters accounted for 3.4\% ( $n$ 60) of the sample and were also excluded (leading to the final sample of 1567 individuals). At this step, the sample was stratified by sex and adjusted for age to analyse associations with UR. Continuous variables are presented as means and standard deviations, while categorical variables are presented as relative frequencies and $95 \%$ CI. Associations between categorical variables were assessed with a $\chi^{2}$ test. Sex-stratified, unconditional logistic regressions ('proc surveylogistic' in SAS) were then carried out to identity factors associated with UR in men and in women. The following confounders were considered in univariate and multivariate analyses: sex; age; BMI; region of residence; educational level; lunch place; snacking frequency; cereal product intake; dairy product intake; high-protein product intake; perception of diet quality; past dieting; sedentary behaviour. All the variables associated with UR with a $P$ value $\leq 0.20$ in the univariate analysis were introduced into the logistic regression model. Collinearity between variables was tested. When two variables were strongly correlated, only one was chosen (depending on its significance level). A backward procedure was used, with a $P$ value of $0 \cdot 10$ required for retention in the model. Analyses were adjusted for age. Odds ratios 
and $95 \%$ CI were calculated. A $P$ value $<0.05$ was considered to be statistically significant.

\section{Results \\ Characteristics of the study population}

Sex distribution in the study sample ( $n$ 1567) was similar to that calculated for the French adult population by the Institut National de la Statistique et des Études Économiques ${ }^{(45)}$ $(\operatorname{men}=48.2 \%$ and women $=51.7 \% \quad v \cdot$ men $=48.6 \%$ and women $=51.4 \%$, respectively), which suggests that valid inferences can be drawn on the basis of the present results.

The characteristics of the participants (stratified by sex) are summarised in Table 1. The mean weight, height, BMI, EI and BMR were higher in men than in women (all $P<0 \cdot 0001$ ). In contrast, there were no significant inter-sex differences in age $(P=0 \cdot 16)$ or $\mathrm{EI} / \mathrm{BMR}(P=0 \cdot 96)$. The prevalence of UR was $24 \%(95 \%$ CI $20 \cdot 4,26 \cdot 8)$ in men and $21 \%(95 \%$ CI $17 \cdot 6$, $23 \cdot 8)$ in women with no statistical difference $(P=0 \cdot 17)$.

\section{Relationships between under-reporting and covariates}

The results of the univariate analysis are presented in Table 2 (for anthropometric, physical activity and socio-economic characteristics) and Table 3 (for dietary habits and perceptions). In men, the anthropometric and socio-economic factors associated with UR were age, BMI and occupation (all $P<0.05$ ). The dietary factors associated with UR were snacking frequency, contributions of proteins and lipids to EI, perception of weight, perception of diet quality and previous weight-loss dieting (all $P<0.05$ ). In women, the anthropometric and socio-economic characteristics associated with UR were BMI, geographical area of residence, educational level, occupation, holidays within the last 3 months, perception of financial situation and financial access to desired foods (all $P<0 \cdot 05$ ). Dietary factors associated with UR were snacking frequency, cereal product intake, contributions of proteins and carbohydrates to EI, perception of weight and perception of diet quality (all $P<0.05$ ).
The results of the multivariate analysis are given in Table 4. UR was independently and negatively associated with age ( $P=0.01$ and $P=0.006$, respectively, in men and women) and positively associated with overweight, obesity $(P<0.0001$ and $P=0.0002$, respectively, in men and women) and protein intake $(P<0.0001$ in both men and women). Men who reported eating lunch in a staff canteen were less likely to be under-reporters $(P=0.004)$, whereas men who stated frequently consuming dairy products $(P=0.04)$ or having a history of restrictive diet consumption were more likely to be under-reporters $(P=0 \cdot 002)$. Women were less likely to underreport their EI if they lived in the Paris region $(P<0 \cdot 0001, v$. the other regions), were more educated $(P=0.03)$, preferred to eat at a family's or friend's home $(P=0 \cdot 04)$ (rather than at home) or reported regular snacking (rather than occasional snacking) $(P=0.0001)$. Women were more likely to underreport if they usually ate lunch at work but not in a staff canteen $(P=0 \cdot 04)$, when they reported weekly consumption of cereal products $(P=0 \cdot 003)$, when they perceived their diet quality to be poor $(P=0.01)$ or when they had a moderate level of sedentary behaviour $(P=0.009)$.

\section{Comparison between the Oxford and Schofield equations for the prediction of $B M R$}

We repeated the same analyses on the basis of the Schofield equation. The BMR, respectively, estimated by the Schofield and Oxford equations displayed a high degree of agreement in terms of the classification of participants according to their reporting status (Supplementary Table 1, available online). Overall, the characteristics associated with UR (age, weight status, contribution of proteins to EI) were the same (Supplementary Table 2, available online). However, there were some minor differences for both men and women. This was especially true for the two variables assessing the PAL, as sedentary behaviour was no longer significantly associated with UR in women and the International Physical Activity Questionnaire score was negatively associated with UR in men.

Table 1. Characteristics of the participants ${ }^{*}$

(Mean values with their standard errors)

\begin{tabular}{|c|c|c|c|c|c|}
\hline & \multicolumn{2}{|c|}{ Men $(n 756)$} & \multicolumn{2}{|c|}{ Women ( $n$ 811) } & \multirow[b]{2}{*}{$P \dagger$} \\
\hline & Mean & SE & Mean & SE & \\
\hline Age (years) & $44 \cdot 3$ & 0.7 & $42 \cdot 9$ & 0.7 & 0.16 \\
\hline Weight (kg) & $77 \cdot 3$ & 0.5 & $62 \cdot 8$ & 0.5 & $<10^{-4}$ \\
\hline Height (cm) & $175 \cdot 2$ & 0.3 & $162 \cdot 6$ & 0.3 & $<10^{-4}$ \\
\hline BMI $\left(\mathrm{kg} / \mathrm{m}^{2}\right)$ & $25 \cdot 2$ & 0.2 & 23.7 & 0.2 & $<10^{-4}$ \\
\hline $\mathrm{El}(\mathrm{MJ} / \mathrm{d})$ & $9 \cdot 4$ & 0.4 & 7.4 & 0.3 & $<10^{-4}$ \\
\hline BMR (MJ/d) & 7.03 & 0.003 & 5.45 & 0.02 & $<10^{-4}$ \\
\hline El:BMR & 1.34 & 0.45 & 1.35 & 0.02 & 0.96 \\
\hline UR (\%) & $\begin{array}{c}\text { Frequency } \\
24\end{array}$ & $\begin{array}{c}95 \% \mathrm{Cl} \\
20 \cdot 4,26 \cdot 8\end{array}$ & $\begin{array}{c}\text { Frequency } \\
21\end{array}$ & $\begin{array}{c}95 \% \mathrm{Cl} \\
17 \cdot 6,23 \cdot 8\end{array}$ & 0.17 \\
\hline
\end{tabular}

El, energy intake; El:BMR, ratio of energy intake to BMR; UR, under-reporting.

* Participants of the Individual and National Study on Food Consumption 2 except pregnant women, people on a diet, people who only reported weight and height without measurements, and over-reporters according to the Oxford equation.

$\dagger P$ according to surveyreg. 
Table 2. Socio-economic and physical activity characteristics of the participants according to declaring status (Oxford's equation for the prediction of BMR), with sex stratification*

(Percentages and $95 \%$ confidence intervals)

\begin{tabular}{|c|c|c|c|c|c|c|c|c|c|c|}
\hline & \multicolumn{4}{|c|}{ Men $(n 756)$} & \multirow[b]{3}{*}{$P \dagger$} & \multicolumn{4}{|c|}{ Women $(n 811)$} & \multirow[b]{3}{*}{$P+$} \\
\hline & \multicolumn{2}{|c|}{ NR $(n 575)$} & \multicolumn{2}{|c|}{ UR $(n 181)$} & & \multicolumn{2}{|c|}{$\mathrm{NR}(n$ 625) } & \multicolumn{2}{|c|}{ UR $(n 186)$} & \\
\hline & $\%$ & $95 \% \mathrm{Cl}$ & $\%$ & $95 \% \mathrm{Cl}$ & & $\%$ & $95 \% \mathrm{Cl}$ & $\%$ & $95 \% \mathrm{Cl}$ & \\
\hline Age (years) & & & & & 0.02 & & & & & 0.92 \\
\hline $18-30$ & $21 \cdot 6$ & $17 \cdot 9,25 \cdot 1$ & 31.9 & $23 \cdot 6,40 \cdot 1$ & & $24 \cdot 3$ & $20 \cdot 4,28.0$ & 24.6 & $17 \cdot 7,31 \cdot 3$ & \\
\hline $31-60$ & 57.5 & $53 \cdot 6,61 \cdot 4$ & $55 \cdot 2$ & $46 \cdot 8,63 \cdot 4$ & & 58.4 & $54 \cdot 2,62 \cdot 4$ & $56 \cdot 7$ & $48 \cdot 1,65 \cdot 3$ & \\
\hline$>60$ & 20.9 & $16 \cdot 9,24 \cdot 8$ & $12 \cdot 9$ & $7 \cdot 0,18 \cdot 8$ & & $17 \cdot 3$ & $13 \cdot 9,20 \cdot 7$ & $18 \cdot 7$ & $11 \cdot 6,25 \cdot 7$ & \\
\hline Weight status & & & & & $<10^{-4}$ & & & & & $<10^{-4}$ \\
\hline Thin & $6 \cdot 0$ & $3 \cdot 9,7.9$ & 3.5 & $0 \cdot 2,6 \cdot 7$ & & 23.8 & $20 \cdot 3,27 \cdot 3$ & $15 \cdot 5$ & $10 \cdot 2,20 \cdot 7$ & \\
\hline Normal & $52 \cdot 2$ & $47 \cdot 9,56 \cdot 4$ & $36 \cdot 0$ & $28 \cdot 0,43 \cdot 8$ & & 48.0 & $43 \cdot 2,52 \cdot 6$ & 31.0 & $23 \cdot 5,38 \cdot 3$ & \\
\hline Overweight & 34.2 & $29 \cdot 7,38.6$ & $40 \cdot 7$ & $32 \cdot 6,48 \cdot 7$ & & $21 \cdot 3$ & $17 \cdot 8,24.8$ & 34.6 & $26 \cdot 6,42 \cdot 5$ & \\
\hline Obese & 7.6 & $5 \cdot 2,9.9$ & $19 \cdot 8$ & $13 \cdot 8,25 \cdot 8$ & & $6 \cdot 8$ & $4.47,9.22$ & 18.9 & $12 \cdot 0,25 \cdot 8$ & \\
\hline Geographical area of residence & & & & & 0.73 & & & & & $<10^{-4}$ \\
\hline North & $46 \cdot 3$ & $39.9,52.5$ & 45.8 & $36 \cdot 7,54.9$ & & $40 \cdot 9$ & $34 \cdot 5,47 \cdot 2$ & 56.5 & $47 \cdot 3,65 \cdot 6$ & \\
\hline Paris region & $18 \cdot 2$ & $15 \cdot 9,20 \cdot 5$ & $20 \cdot 6$ & $17 \cdot 1,23 \cdot 9$ & & $20 \cdot 2$ & $17 \cdot 9,22 \cdot 5$ & $14 \cdot 1$ & $11 \cdot 5,16 \cdot 6$ & \\
\hline South & 35.5 & $29 \cdot 1,41 \cdot 7$ & 33.6 & $24 \cdot 7,42 \cdot 4$ & & 38.9 & $32 \cdot 7,44.9$ & 29.4 & $21 \cdot 3,37 \cdot 4$ & \\
\hline Educational level & & & & & 0.84 & & & & & $<10^{-4}$ \\
\hline Primary school & 13.9 & $10 \cdot 6,17 \cdot 1$ & 12.9 & $7 \cdot 13,18 \cdot 6$ & & $17 \cdot 1$ & $13 \cdot 8,20 \cdot 3$ & 38.8 & $29 \cdot 5,47 \cdot 9$ & \\
\hline Secondary school & $55 \cdot 6$ & $51 \cdot 5,59 \cdot 7$ & $58 \cdot 2$ & $50 \cdot 7,65.5$ & & $47 \cdot 1$ & $43 \cdot 0,51 \cdot 2$ & $41 \cdot 1$ & $32 \cdot 7,49 \cdot 4$ & \\
\hline University & 30.4 & $26 \cdot 7,34 \cdot 1$ & 28.9 & $22 \cdot 0,35 \cdot 8$ & & 35.8 & $31 \cdot 6,39.8$ & $20 \cdot 1$ & $14 \cdot 6,25 \cdot 6$ & \\
\hline Occupation & & & & & 0.04 & & & & & 0.002 \\
\hline Farmers or junior managers & $20 \cdot 6$ & $16 \cdot 6,24 \cdot 5$ & 21.5 & $15 \cdot 1,27 \cdot 8$ & & $19 \cdot 4$ & $15 \cdot 9,22 \cdot 8$ & $13 \cdot 8$ & $8 \cdot 43,19 \cdot 1$ & \\
\hline Workers & 29.8 & $25 \cdot 3,34 \cdot 2$ & 41.0 & $32 \cdot 9,49 \cdot 1$ & & 29.9 & $25 \cdot 5,34 \cdot 1$ & $42 \cdot 4$ & $33 \cdot 1,51 \cdot 6$ & \\
\hline Senior managers & $12 \cdot 2$ & $9.9,14.4$ & $11 \cdot 0$ & $6 \cdot 14,15 \cdot 8$ & & $9 \cdot 0$ & $6 \cdot 55,11 \cdot 3$ & $2 \cdot 6$ & $1.54,3.72$ & \\
\hline Homemakers or students & 37.3 & $32 \cdot 8,41 \cdot 8$ & $26 \cdot 4$ & $18 \cdot 8,34.0$ & & 41.8 & $37 \cdot 0,46 \cdot 5$ & $41 \cdot 2$ & $32 \cdot 7,49 \cdot 6$ & \\
\hline Holidays within the last 3 months & & & & & 0.18 & & & & & 0.02 \\
\hline Yes & 71.8 & $67 \cdot 5,76 \cdot 0$ & $66 \cdot 0$ & $58 \cdot 3,73 \cdot 6$ & & 34.0 & $26 \cdot 3,41 \cdot 6$ & 57.5 & $49 \cdot 1,65 \cdot 8$ & \\
\hline No & $28 \cdot 2$ & $23 \cdot 9,32 \cdot 4$ & $34 \cdot 0$ & $26 \cdot 3,41 \cdot 6$ & & $30 \cdot 8$ & $26 \cdot 4,35 \cdot 1$ & 42.5 & $34 \cdot 1,50 \cdot 8$ & \\
\hline Perception of financial situation & & & & & & & & & & \\
\hline Good & $58 \cdot 2$ & $54 \cdot 0,62 \cdot 3$ & 57.9 & $50 \cdot 2,65 \cdot 4$ & 0.99 & $56 \cdot 5$ & $51.9,61.0$ & $48 \cdot 2$ & $40 \cdot 1,56 \cdot 3$ & 0.01 \\
\hline Moderate & 34.9 & $30 \cdot 9,38 \cdot 7$ & $34 \cdot 8$ & $27 \cdot 6,42 \cdot 0$ & & $38 \cdot 3$ & $33 \cdot 8,42 \cdot 8$ & $40 \cdot 6$ & $32 \cdot 8,48 \cdot 3$ & \\
\hline Poor & 6.9 & $4 \cdot 5,9 \cdot 2$ & $7 \cdot 3$ & $2 \cdot 82,11 \cdot 7$ & & $5 \cdot 2$ & $3.32,6.99$ & $11 \cdot 2$ & $6 \cdot 05,16 \cdot 4$ & \\
\hline Financial access to desired foods & & & & & 0.74 & & & & & $<10^{-4}$ \\
\hline Good & $86 \cdot 3$ & $82 \cdot 8,89 \cdot 6$ & 88.7 & $83.4,94.0$ & & 84.6 & $81 \cdot 3,87 \cdot 8$ & 68.4 & $61 \cdot 4,77 \cdot 3$ & \\
\hline Moderate & $12 \cdot 8$ & $9.51,16.0$ & $10 \cdot 3$ & $5 \cdot 13,15 \cdot 5$ & & 14.9 & $11 \cdot 7,18 \cdot 0$ & 28.0 & $20 \cdot 7,35 \cdot 2$ & \\
\hline Poor & 0.9 & $0.1,1 \cdot 6$ & 0.9 & $0.2,2.48$ & & 0.5 & $0.03,0.90$ & 2.6 & $0 \cdot 1,5 \cdot 2$ & \\
\hline Sedentary behaviour & & & & & 0.36 & & & & & 0.1 \\
\hline Low & 29.9 & $25 \cdot 9,33.8$ & $25 \cdot 5$ & $19 \cdot 3,31 \cdot 7$ & & $38 \cdot 3$ & $34 \cdot 1,42 \cdot 5$ & $29 \cdot 8$ & $22 \cdot 3,37 \cdot 1$ & \\
\hline Moderate & $35 \cdot 7$ & $31 \cdot 0,40 \cdot 3$ & $34 \cdot 0$ & $26 \cdot 4,41.5$ & & 32.9 & $28 \cdot 7,37 \cdot 0$ & 41.5 & $32 \cdot 2,50 \cdot 8$ & \\
\hline High & 34.4 & $30 \cdot 0,38 \cdot 7$ & 40.5 & $32 \cdot 1,48 \cdot 7$ & & $28 \cdot 7$ & $25 \cdot 0,32 \cdot 4$ & 28.7 & $21 \cdot 6,35 \cdot 7$ & \\
\hline MVPA level & & & & & 0.20 & & & & & 0.68 \\
\hline Low & $22 \cdot 6$ & $18 \cdot 5,26 \cdot 6$ & $28 \cdot 0$ & $20 \cdot 9,35 \cdot 1$ & & 24.6 & $20 \cdot 5,28 \cdot 5$ & $25 \cdot 3$ & $17 \cdot 2,33 \cdot 3$ & \\
\hline Moderate & $31 \cdot 8$ & $27 \cdot 8,35 \cdot 7$ & $25 \cdot 7$ & $19 \cdot 2,32 \cdot 0$ & & $34 \cdot 2$ & $29.5,38.8$ & $37 \cdot 2$ & $29 \cdot 6,44 \cdot 8$ & \\
\hline High & $45 \cdot 6$ & $41 \cdot 1,50 \cdot 1$ & $46 \cdot 3$ & $38 \cdot 2,54 \cdot 4$ & & 41.3 & $36 \cdot 5,45 \cdot 9$ & 37.4 & $30 \cdot 0,44 \cdot 8$ & \\
\hline
\end{tabular}

NR, normal reporters; UR, under-reporters; MVPA, moderate-to-vigorous intensity physical activity.

* Participants of the Individual and National Study on Food Consumption 2 except pregnant women, people on a diet, people who only reported weight and height without measurements, and over-reporters according to the Oxford equation.

$\dagger \chi^{2}$ test between the UR and NR groups, within each sex.

\section{Discussion}

In the present study of a representative sample of the French adult population based on the collection of validated food intake data, the overall prevalence of UR was $22.5 \%$. This value was similar in men and women; however, several characteristics of under-reporters differed according to sex. Earlier studies ${ }^{(7,23-27,31,46-55)}$ have reported overall UR rates ranging from about $10 \%$ to up to $60 \%$, depending on methodological constraints (e.g. dietary intake data collection and EE measurement or estimation methods) and the characteristics of the study population (sex, age, BMI and PAL) ${ }^{(27)}$. The prevalence of $22.5 \%$ found in the present study falls within the range of values recorded in other European populations - especially when a similar methodology is used $^{(25,31,47,49,50)}$. For instance, the prevalence of UR was $26 \%$ in a survey of 2000 Swedish men and women aged from 1 to 74 years, using a $7 \mathrm{~d}$ record and a PAL cut-off of $1 \cdot 27^{(49)}$. In a study that used the 'gold standard' doubly labelled water method for the evaluation of EE, the prevalence of UR in a similar Anglo-Saxon population of adults was $20 \%{ }^{(46)}$, which is close to the prevalence found for the French adult population in the present study.

The method used for the estimation of UR must be sensitive, specific and accurate. Of the various BMR prediction 
Table 3. Food habits and perception characteristics of the participants according to declaring status (Oxford's equation for the prediction of BMR), with sex stratification*

(Percentages and $95 \%$ confidence intervals)

\begin{tabular}{|c|c|c|c|c|c|c|c|c|c|c|}
\hline & \multicolumn{4}{|c|}{ Men $(n 756)$} & \multirow[b]{3}{*}{$P \dagger$} & \multicolumn{4}{|c|}{ Women $(n 811)$} & \multirow[b]{3}{*}{$P \dagger$} \\
\hline & \multicolumn{2}{|c|}{ NR $(n 575)$} & \multicolumn{2}{|c|}{ UR $(n 181)$} & & \multicolumn{2}{|c|}{ NR $(n$ 625) } & \multicolumn{2}{|c|}{ UR $(n 186)$} & \\
\hline & $\%$ & $95 \% \mathrm{Cl}$ & $\%$ & $95 \% \mathrm{Cl}$ & & $\%$ & $95 \% \mathrm{Cl}$ & $\%$ & $95 \% \mathrm{Cl}$ & \\
\hline Place of lunch & & & & & $0 \cdot 12$ & & & & & 0.19 \\
\hline At home & $63 \cdot 2$ & $58 \cdot 9,67 \cdot 4$ & $58 \cdot 7$ & $51 \cdot 3,65 \cdot 9$ & & 73.2 & $69.4,76.9$ & $74 \cdot 0$ & $66 \cdot 6,81 \cdot 3$ & \\
\hline Staff canteen & $16 \cdot 1$ & $12 \cdot 8,19 \cdot 2$ & $12 \cdot 8$ & $8 \cdot 7,16 \cdot 8$ & & 8.6 & $6 \cdot 45,10 \cdot 7$ & $9 \cdot 0$ & $5 \cdot 3,12 \cdot 6$ & \\
\hline At work $\ddagger$ & $12 \cdot 1$ & $9 \cdot 3,14 \cdot 7$ & $18 \cdot 0$ & $11.4,24.4$ & & $10 \cdot 1$ & $7 \cdot 49,12 \cdot 8$ & 13.8 & $7 \cdot 1,20 \cdot 4$ & \\
\hline Family member's or friend's home & $1 \cdot 8$ & $0 \cdot 9,2 \cdot 7$ & $1 \cdot 2$ & $0 \cdot 2,2 \cdot 6$ & & $2 \cdot 1$ & $0.73,3.43$ & $1 \cdot 0$ & $0 \cdot 2,2 \cdot 3$ & \\
\hline Fast-food restaurant & $6 \cdot 8$ & $4.9,8.7$ & 9.5 & $4.43,14.4$ & & 5.9 & $4.02,7.85$ & $2 \cdot 3$ & $0.7,3.8$ & \\
\hline Fast-food consumption & & & & & 0.87 & & & & & 0.41 \\
\hline Occasionally or never & $83 \cdot 2$ & $86 \cdot 6,91 \cdot 7$ & $89 \cdot 7$ & $84.7,94.5$ & & $95 \cdot 3$ & $93.7,96 \cdot 9$ & 93.7 & $89 \cdot 8,97 \cdot 6$ & \\
\hline Regularly & $10 \cdot 8$ & $8 \cdot 2,13 \cdot 3$ & $10 \cdot 3$ & $5 \cdot 4,15 \cdot 2$ & & 4.7 & $3.04,6 \cdot 27$ & $6 \cdot 3$ & $2 \cdot 38,10 \cdot 1$ & \\
\hline Resort to vending machine & & & & & 0.37 & & & & & 0.49 \\
\hline Occasionally or never & 91.9 & $88 \cdot 1,93 \cdot 0$ & $90 \cdot 1$ & $84 \cdot 3,95 \cdot 8$ & & 91.9 & $88.8,94.9$ & 91.7 & $87 \cdot 7,95 \cdot 5$ & \\
\hline Regularly & $7 \cdot 1$ & $6 \cdot 1,11 \cdot 0$ & $7 \cdot 2$ & $2 \cdot 49,11 \cdot 8$ & & 7.5 & $4.45,10.5$ & $6 \cdot 8$ & $3 \cdot 15,10 \cdot 4$ & \\
\hline Don’t know & $1 \cdot 0$ & $0 \cdot 1,1 \cdot 8$ & $2 \cdot 7$ & $0 \cdot 1,6 \cdot 2$ & & 0.6 & $0.09,1.15$ & 1.5 & $0.3-3.29$ & \\
\hline Snacking frequency & & & & & 0.01 & & & & & $<10^{-4}$ \\
\hline Occasionally or never & $29 \cdot 7$ & $25 \cdot 2,34 \cdot 1$ & $24 \cdot 1$ & $17 \cdot 7,30 \cdot 4$ & & 22.5 & $19 \cdot 0,25 \cdot 9$ & $28 \cdot 1$ & $20 \cdot 5,35 \cdot 6$ & \\
\hline Regularly & $40 \cdot 8$ & $36 \cdot 3,45 \cdot 2$ & $34 \cdot 2$ & $26 \cdot 7,41 \cdot 6$ & & 61.6 & $57 \cdot 7,65 \cdot 4$ & 31.8 & $24 \cdot 0,39 \cdot 6$ & \\
\hline Don't know & 29.5 & $25 \cdot 5,33 \cdot 4$ & 41.7 & $34 \cdot 0,49 \cdot 3$ & & $15 \cdot 9$ & $13 \cdot 0,18 \cdot 7$ & $40 \cdot 1$ & $30 \cdot 6,49 \cdot 4$ & \\
\hline Cereal product intake & & & & & 0.09 & & & & & $<10^{-4}$ \\
\hline Every day & $81 \cdot 6$ & $78 \cdot 1,85 \cdot 1$ & $76 \cdot 2$ & $69 \cdot 3,83 \cdot 0$ & & 87.5 & $84 \cdot 3,90 \cdot 5$ & $70 \cdot 4$ & $62 \cdot 3,78 \cdot 5$ & \\
\hline Every week & $9 \cdot 1$ & $6 \cdot 4,11 \cdot 6$ & 14.9 & $8 \cdot 77,21 \cdot 0$ & & 7.9 & $5 \cdot 2,10 \cdot 5$ & $19 \cdot 2$ & $11 \cdot 9,26 \cdot 4$ & \\
\hline Don’t know & $9 \cdot 3$ & $6 \cdot 6,11.9$ & 8.9 & $4 \cdot 71,12 \cdot 9$ & & 4.6 & $2 \cdot 8,6 \cdot 4$ & $10 \cdot 4$ & $5 \cdot 22,15 \cdot 5$ & \\
\hline Dairy product§ intake & & & & & 0.05 & & & & & 0.13 \\
\hline Every day & 91.6 & $89 \cdot 2,93.9$ & $85 \cdot 2$ & $79 \cdot 2,91 \cdot 0$ & & 93.8 & $91 \cdot 7,95 \cdot 8$ & $89 \cdot 6$ & $84.6,94.5$ & \\
\hline Every week & 3.6 & $2 \cdot 1,4 \cdot 9$ & $7 \cdot 0$ & $3 \cdot 24,10 \cdot 8$ & & $2 \cdot 7$ & $1.5,3.8$ & 5.9 & $1.80,9.97$ & \\
\hline Don't know & $4 \cdot 8$ & $3 \cdot 1,6 \cdot 5$ & $7 \cdot 8$ & $3 \cdot 17,12 \cdot 4$ & & 3.5 & $1 \cdot 8,5 \cdot 1$ & 4.5 & $1.56,7.40$ & \\
\hline Protein product|| intake & & & & & 0.93 & & & & & 0.09 \\
\hline Every day & $70 \cdot 8$ & $66 \cdot 4,75 \cdot 1$ & 71.4 & $63 \cdot 4,79 \cdot 2$ & & $75 \cdot 7$ & $71 \cdot 6,79 \cdot 8$ & 68.4 & $60 \cdot 6,76 \cdot 0$ & \\
\hline Every week & $21 \cdot 3$ & $17 \cdot 2,25 \cdot 2$ & 21.7 & $14 \cdot 7,28 \cdot 6$ & & 20.5 & $16 \cdot 3,24 \cdot 6$ & $24 \cdot 3$ & $17 \cdot 3,31 \cdot 2$ & \\
\hline Don't know & 7.9 & $5 \cdot 3,10 \cdot 5$ & 6.9 & $3.06,10 \cdot 8$ & & 3.7 & $2 \cdot 3,5 \cdot 2$ & $7 \cdot 4$ & $3.31,11 \cdot 3$ & \\
\hline Contribution of proteins to El & & & & & $<10^{-4}$ & & & & & $<10^{-4}$ \\
\hline Low & $37 \cdot 2$ & $32.4,41.9$ & $12 \cdot 9$ & $8 \cdot 16,17 \cdot 7$ & & 39.2 & $35 \cdot 0,43 \cdot 2$ & $20 \cdot 9$ & $13 \cdot 9,27 \cdot 9$ & \\
\hline Intermediate & 34.4 & $30 \cdot 2,38 \cdot 5$ & $30 \cdot 2$ & $22 \cdot 7,37 \cdot 7$ & & 35.5 & $31.4,39.5$ & $25 \cdot 2$ & $17 \cdot 8,32 \cdot 5$ & \\
\hline High & 28.4 & $24 \cdot 1,32 \cdot 6$ & $56 \cdot 8$ & $49 \cdot 3,64 \cdot 2$ & & $25 \cdot 4$ & $21 \cdot 3,29 \cdot 3$ & 53.9 & $45 \cdot 4,62 \cdot 3$ & \\
\hline Contribution of carbohydrates to El & & & & & 0.33 & & & & & 0.03 \\
\hline Low & $36 \cdot 7$ & $32 \cdot 5,40 \cdot 7$ & $42 \cdot 6$ & $35 \cdot 4,49 \cdot 6$ & & 28.7 & $24 \cdot 9,32 \cdot 4$ & $40 \cdot 4$ & $32 \cdot 2,48 \cdot 4$ & \\
\hline Intermediate & $33 \cdot 6$ & $29.5,37.6$ & $29 \cdot 0$ & $22 \cdot 4,35 \cdot 4$ & & $35 \cdot 7$ & $31.7,39.7$ & $27 \cdot 6$ & $20 \cdot 1,35 \cdot 1$ & \\
\hline High & $29 \cdot 7$ & $25 \cdot 8,33 \cdot 6$ & $28 \cdot 4$ & $21 \cdot 4,35 \cdot 4$ & & $35 \cdot 6$ & $31 \cdot 1,39 \cdot 9$ & 32 & $24 \cdot 5,39 \cdot 4$ & \\
\hline Contribution of lipids to $\mathrm{EI}$ & & & & & 0.02 & & & & & 0.49 \\
\hline Low & $37 \cdot 6$ & $33.3,41 \cdot 9$ & $32 \cdot 4$ & $25 \cdot 2,39 \cdot 5$ & & 21.5 & $18 \cdot 1,24 \cdot 8$ & $25 \cdot 3$ & $18 \cdot 1,32 \cdot 3$ & \\
\hline Intermediate & $36 \cdot 8$ & $32 \cdot 6,40.9$ & $30 \cdot 2$ & $22 \cdot 9,37.5$ & & $30 \cdot 1$ & $26 \cdot 1,33 \cdot 9$ & 31.7 & $24 \cdot 5,38 \cdot 7$ & \\
\hline High & $25 \cdot 5$ & $21.5,29.5$ & $37 \cdot 4$ & $29 \cdot 6,45 \cdot 1$ & & $48 \cdot 4$ & $44 \cdot 1,52 \cdot 7$ & 43.1 & $34 \cdot 6,51 \cdot 5$ & \\
\hline Perception of diet quality & & & & & 0.01 & & & & & 0.01 \\
\hline Good & $54 \cdot 0$ & $49 \cdot 2,58 \cdot 6$ & $48 \cdot 0$ & $40 \cdot 7,55 \cdot 2$ & & 51.3 & $46 \cdot 9,55 \cdot 5$ & $37 \cdot 3$ & $29 \cdot 4,45 \cdot 1$ & \\
\hline Not good & $18 \cdot 4$ & $15 \cdot 0,21 \cdot 7$ & $29 \cdot 3$ & $23 \cdot 2,35 \cdot 2$ & & $23 \cdot 2$ & $19 \cdot 5,26 \cdot 8$ & $31 \cdot 8$ & $23 \cdot 4,40 \cdot 0$ & \\
\hline Don’t know & $27 \cdot 7$ & $23 \cdot 6,31 \cdot 7$ & $22 \cdot 7$ & $15 \cdot 6,29 \cdot 7$ & & $25 \cdot 5$ & $21 \cdot 5,29 \cdot 4$ & 30.9 & $22 \cdot 2,39.5$ & \\
\hline Perception of weight & & & & & $<10^{-3}$ & & & & & 0.009 \\
\hline Normal & $66 \cdot 0$ & $61 \cdot 7,70 \cdot 1$ & $48 \cdot 8$ & $41 \cdot 4,56 \cdot 1$ & & $56 \cdot 2$ & $51 \cdot 9,60 \cdot 5$ & $41 \cdot 2$ & $33 \cdot 7,48 \cdot 6$ & \\
\hline Overweight & $26 \cdot 5$ & $22 \cdot 8,30 \cdot 2$ & 44.7 & $37 \cdot 1,52 \cdot 1$ & & $35 \cdot 1$ & $30.9,39.3$ & $47 \cdot 6$ & $39 \cdot 4,55 \cdot 6$ & \\
\hline Too thin & $6 \cdot 1$ & $4 \cdot 2,7 \cdot 9$ & $3 \cdot 8$ & $0.11,7.4$ & & 3.7 & $2 \cdot 1,5 \cdot 3$ & 3.4 & $1 \cdot 3,5 \cdot 5$ & \\
\hline Don’t know & 1.4 & $0.3,2.4$ & $2 \cdot 7$ & $0.1,5.6$ & & 4.9 & $2 \cdot 9,6 \cdot 9$ & $7 \cdot 8$ & $2 \cdot 9,12 \cdot 6$ & \\
\hline Past slimming diet & & & & & $<10^{-4}$ & & & & & 0.17 \\
\hline Yes & $9 \cdot 0$ & $6 \cdot 2,11 \cdot 8$ & 21.9 & $15 \cdot 5,28 \cdot 3$ & & $32 \cdot 1$ & $28 \cdot 3,35 \cdot 7$ & $38 \cdot 1$ & $30 \cdot 5,45 \cdot 7$ & \\
\hline No & 91.0 & $88 \cdot 1,93 \cdot 7$ & 78.1 & $71 \cdot 6,84 \cdot 4$ & & 67.9 & $64.2,71.6$ & 61.9 & $54 \cdot 2,69 \cdot 4$ & \\
\hline
\end{tabular}

NR, normo-reporters; UR, under-reporters; El, energy intake.

*Participants of the Individual and National Study on Food Consumption 2 except pregnant women, people on a diet, people who only reported weight and height without measurements, and over-reporters according to the Oxford equation.

$\dagger \chi^{2}$ test.

$\ddagger$ At work but not in the canteen.

$\S$ Milk, ultra-spawns dairy and cheese.

|| Meat, poultry, fish and eggs. 
Table 4. Under-reporting according to sociodemographic, anthropometric, behavioural and nutritional variables (Oxford equation for the prediction of BMR)*

(Odds ratios and $95 \%$ confidence intervals)

\begin{tabular}{|c|c|c|c|c|c|c|}
\hline & \multicolumn{2}{|c|}{ Men $(n 756)$} & \multirow[b]{2}{*}{$P \dagger$} & \multicolumn{2}{|c|}{ Women $(n 811)$} & \multirow[b]{2}{*}{$P \dagger$} \\
\hline & OR & $95 \% \mathrm{Cl}$ & & OR & $95 \% \mathrm{Cl}$ & \\
\hline Age (ref: 18-30) (years) & 1 & - & 0.01 & 1 & - & 0.006 \\
\hline $31-60$ & 0.4 & $0.3,0.8$ & & 0.8 & $0.5,1.4$ & \\
\hline$>60$ & 0.3 & $0.1,0.7$ & & 0.2 & $0.1,0.6$ & \\
\hline Weight status (ref: normal) & 1 & - & $<10^{-4}$ & 1 & - & 0.0002 \\
\hline Thin & 1.0 & $0.4,3.0$ & & 1.0 & $0.5,1.9$ & \\
\hline Overweight & $2 \cdot 1$ & $1 \cdot 3,3 \cdot 6$ & & $2 \cdot 1$ & $1 \cdot 2,3 \cdot 8$ & \\
\hline Obese & $4 \cdot 2$ & $2 \cdot 3,7 \cdot 8$ & & $5 \cdot 4$ & $2 \cdot 1,14 \cdot 1$ & \\
\hline Geographical area of residence (ref: North) & & & & 1 & - & 0.0002 \\
\hline Paris region & & & & 0.3 & $0.2,0.6$ & \\
\hline South & & & & 0.6 & $0.3,1 \cdot 1$ & \\
\hline Educational level (ref: primary school) & & & & 1 & - & 0.07 \\
\hline Secondary school & & & & 0.5 & $0.2,0.9$ & \\
\hline University & & & & 0.4 & $0.2,0.9$ & \\
\hline Place of lunch (ref: at home) & 1 & - & 0.04 & 1 & - & 0.02 \\
\hline Staff canteen & 0.4 & $0.2,0.8$ & & $2 \cdot 1$ & $0.9,5 \cdot 1$ & \\
\hline At work $\ddagger$ & $1 \cdot 2$ & $0 \cdot 6,2 \cdot 2$ & & $2 \cdot 0$ & $1 \cdot 1,4 \cdot 1$ & \\
\hline Family member's or friend's home & 0.6 & $0.2,2 \cdot 0$ & & 0.1 & $0.1,0.8$ & \\
\hline Fast-food restaurant & 0.9 & $0.4,1.8$ & & 0.5 & $0.2,1.6$ & \\
\hline Snacking frequency (ref: occasionally or never) & & & & 1 & - & $<10^{-4}$ \\
\hline Regularly & & & & 0.3 & $0.2,0.6$ & \\
\hline Don’t know & & & & $2 \cdot 5$ & $1 \cdot 3,4.6$ & \\
\hline Cereal product intake (ref: every day) & 1 & - & 0.03 & 1 & - & 0.01 \\
\hline Every week & 1.6 & $0.8,3.0$ & & $3 \cdot 2$ & $1.4,6 \cdot 9$ & \\
\hline Don't know & 0.4 & $0.2,0.9$ & & 1.6 & $0.6,4 \cdot 1$ & \\
\hline Dairy§ product intake (ref: every day) & 1 & - & 0.003 & & & \\
\hline Every week & $2 \cdot 1$ & $1 \cdot 1,4 \cdot 7$ & & & & \\
\hline Don't know & 3.4 & $1 \cdot 4,8 \cdot 2$ & & & & \\
\hline Protein product|| intake (ref: low) & 1 & - & $<10^{-4}$ & 1 & - & $<10^{-4}$ \\
\hline Intermediate & $2 \cdot 3$ & $1 \cdot 3,4 \cdot 1$ & & $1 \cdot 2$ & $0.7,2 \cdot 2$ & \\
\hline High & 5.9 & $3 \cdot 5,10 \cdot 1$ & & $3 \cdot 8$ & $2 \cdot 2,6 \cdot 7$ & \\
\hline Perception of diet quality (ref: good) & & & & 1 & - & 0.04 \\
\hline Not good & & & & $2 \cdot 0$ & $1 \cdot 1,3.5$ & \\
\hline Don’t know & & & & 1.3 & $0.7,2 \cdot 2$ & \\
\hline Past slimming diet (ref: no) & 1 & - & 0.002 & & & \\
\hline Yes & $2 \cdot 4$ & $1 \cdot 4,4 \cdot 2$ & & & & \\
\hline Sedentary behaviour (ref: low) & & & & 1 & - & 0.02 \\
\hline Moderate & & & & $2 \cdot 1$ & $1 \cdot 2,3 \cdot 6$ & \\
\hline High & & & & $1 \cdot 2$ & $0.7,2 \cdot 3$ & \\
\hline
\end{tabular}

* Participants of the Individual and National Study on Food Consumption 2 except pregnant women, people on a diet, people who only reported weight and height without measurements, and over-reporters according to the Oxford equation.

†Stepwise multivariate logistic regression analysis ( $P$ of the model). Only the OR of the variables selected by the stepwise logistic regression are given.

$\ddagger$ At work but not in the canteen.

$\S$ Milk, ultra-spawns dairy and cheese.

|| Meat, poultry, fish and eggs.

equations published to date, those of Mifflin et $a .^{(14)}$, Schofield ${ }^{(11)}$, Müller et al. ${ }^{(15)}$ and Oxford ${ }^{(16)}$ are used particularly frequently. An equation is considered as validated if, when applied to a population other than the one originally used for derivation, $70-75 \%$ of the participants are correctly assigned an energy requirement within $10 \%$ of the measured value $^{(56)}$. Thus, it is particularly important to choose a prediction equation derived from a population that is as similar as possible to the study population. In the present study, we chose the Oxford equation because the derivative population was broader than that used by Schofield ${ }^{(11,16,56)}$. However, the prevalence of UR estimated using the Oxford equation - used in the present study for the first time for a representative sample of the adult population across France - provided much the same results as those obtained using the Schofield equation (in terms of both prevalence and classification). This suggests that the use of the Oxford equation would not distort comparisons between the successive INCA surveys.

We found a similar prevalence of UR in men and women. The literature on the effect of sex on UR remains unclear; women are more inclined to under-report than men in most $^{(10,18,25-28)}$ but not in all studies ${ }^{(27,52-57)}$. The reasons for this disparity may be related to differences in study design (age range and exclusion criteria for the final sample), cultural factors related to each participant's perception of his/her dietary intake or inter-country differences in social pressure for body-shape aesthetic references. Indeed, earlier research on sex differences in energy reporting has suggested that women are more sensitive to the social pressure to conform to an expected image, which may result in 
UR of $\mathrm{EI}^{(18,44,58,59)}$. Recent reports have suggested that this pressure is now much the same for men and women in France, which may explain a similar prevalence of UR in men and women in the present study ${ }^{(60)}$

In addition to estimating the prevalence of UR, we sought to characterise under-reporters. We found that BMI, age, the usual lunch place, a lower frequency of consumption of some food groups and the contribution of proteins to EI were associated with UR. In agreement with the findings of most of the other studies, overweight was strongly and positively associated with $\mathrm{UR}^{(18,21,27,31,49,51,61)}$; for instance, Freisling et al. ${ }^{(51)}$ estimated that the probability of being identified as an underreporter increased by $66 \%$ for each five unit in adjusted BMI. Similarly, older people were less likely to under-report their EI, an observation that remains subject to debate ${ }^{(18,25,61)}$, as elderly subjects are more likely to display recall bias during data collection $^{(23,25)}$. However, others have shown that healthy older adults report as accurately as young adults do ${ }^{(62)}$. To the best of our knowledge, the influence of a person's usual lunch place has never been investigated previously in adults. In the present study, men/women were less likely to underreport 'when they usually ate lunch in a staff canteen (rather than at home)'/'when then usually ate lunch in a friend's or family member's home'. Similarly, in the INCA2 study of children $^{(29)}$, eating regularly in the school canteen was found to be inversely associated with UR. These associations may reflect more structured eating behaviours, which may decrease the rate of UR. Lastly, UR was associated with the intake of certain foods and/or nutrients. Indeed, self-reporting of food and nutrient intake tends to depend on how socially desirable they are perceived to be $\mathrm{b}^{(17,18,20,33,58,59)}$. Similar differences have been observed in both men and women, with a lower frequency of consumption (rather than the reported portion size) being related to $\mathrm{UR}^{(63)}$. Notably, the contribution of protein-containing foods to EI was positively and strongly associated with UR in both men and women, which may suggest that these participants under-report their carbohydrate and/or lipid intake. The use of 'gold standard' biomarkers is still the only way to accurately measure macronutrient intake. For instance, the true prevalence of UR for protein intake in the Observing Energy and Protein Nutrition (OPEN) study (in which urinary $\mathrm{N}$ was used as a biomarker of protein intake $v$. $24 \mathrm{~h}$ dietary recall) ranged from 11 to $15 \%{ }^{(46)}$.

Educational level and geographical area of residence were independently associated with UR in women. Most studies carried out in adults have shown that UR is more prevalent in groups with a lower educational level - probably due to the skills needed to complete diet questionnaires accurately and less time investment in nutritional matters ${ }^{(18,28,29)}$. The association between UR and the geographical area of residence is poorly documented. In the present study, women living in the Paris region were less likely to under-report than those living in northern or southern France. Similar regional associations have been reported in Japan ${ }^{(50)}$ and Poland ${ }^{(52)}$, which may be related to cultural factors or urban lifestyle. A higher snacking frequency was associated with less UR, which may be related to a higher EI Indeed, this observation first demonstrates that the EI of snacking women is high enough to balance their
$\mathrm{EE}^{(8,9,18,64)}$. Then, further analyses should be carried out to discriminate the respective contribution of snacks and that of meals to the total EI and to identify eventual specific food patterns or specific behaviour in this population. On the other hand, poor perception of one's diet quality was also related to UR, which may suggest that foods with a poor image tend to be omitted from food records more frequently. Lastly, the present study is the first to report that female under-reporters are also characterised by a moderate level of sedentary behaviour, which may be related to health awareness attitudes. Similarly, a history of slimming was specifically associated with $\mathrm{UR}^{(65)}$.

Besides the inherent limitations of a cross-sectional design and the possible existence of confounding factors that were not taken into account, few other limitations have to be mentioned. First, BMR was estimated using prediction equations and not measured with 'gold standard' methods (such as doubly labelled water). Biomarker-based methods have been used sometimes in large national populations ${ }^{(66-69)}$ or in calibration studies among multicentre epidemiological surveys $^{(70)}$. However, their use remains limited because of their cost burden. Second, the value of PAL entered into Goldberg's criterion was chosen from the theoretical estimations provided by the World Health Organization some years ago ${ }^{(44)}$ rather than from specific studies on the energy expended in physical activity by the study population. Nevertheless, the best method for handling this fundamental issue is still subject to debate, and different methods and values of PAL have been suggested by various task forces, researchers ${ }^{(43,71,72)}$ and European expert panels ${ }^{(56,73)}$. The difficulty in choosing a value of PAL judged to be appropriate to a studied population partly lies in the main methods used to measure or to estimate PAL: biomarker-based methods ${ }^{(44,56,73-75)}$; adequate bibliography when available ${ }^{(58)}$; theoretical values proposed by panel reports ${ }^{(44,73-76)}$. It has also to be pointed out that the measures of moderate-to-vigorous intensity physical activity levels, determined using a lifestyle questionnaire such as the International Physical Activity Questionnaire, that were estimated were not adequate for estimating the value of the PAL component of total EE with accuracy ${ }^{(73)}$. However, in the present study, as the theoretical value of PAL proposed by the World Health Organization ${ }^{(44)}$ for a sedentary lifestyle population was chosen, we assume that a misclassification of more active participants could exist. Lastly, an inherent limitation of the design of the present study is that it was not able to distinguish between restraint-eaters ${ }^{(18)}$ and under-reporters.

A major strength of the present study is the use of a nationally representative sample (the INCA2 survey participants) for which many parameters related to food intake, socio-economic status, weight status, weight perception, physical activity and sedentary behaviour were recorded. The representativeness of the sample was ensured by (1) the sampling design, with randomisation and weighting, (2) the good participation rate (63\%) and (3) the low missing data rate. The present study constitutes a wide-ranging investigation of UR covariates and provides novel insights into this issue in adults. Moreover, the large number of participants enabled us to stratify by sex and analyse UR for the three age classes in the BMR prediction equations. The usual day-to-day variability in food intake was taken into 
account during $7 \mathrm{~d}$ recordings in most cases, which also constitutes a strength. Lastly, the fact that we objectively measured weight and height improved the robustness of two important criteria (the definition of UR and the BMI values of the participants) ${ }^{(77-79)}$.

In conclusion, the present study highlights the diversity of the characteristics associated with UR in a French adult population and provides new insights, which should be investigated deeply. Some of these characteristics are related to dietary habits (e.g. snacking), suggesting that the methods used to collect dietary intake data should focus specifically on these factors. Other identified factors were related to the physiological characteristics of the participants (e.g. weight status), which influence the prediction of BMR.

\section{Supplementary material}

To view supplementary material for this article, please visit http://dx.doi.org/10.1017/S0007114513003759

\section{Acknowledgements}

The authors thank Francis Guillemin for discussions and Colin Haslock for proof reading the manuscript for English language.

The study was supported by ANSES for the design and conduct of the study, analysis of the data, interpretation of the findings and preparation of the manuscript.

The authors' contributions are as follows: I. B. V. designed the study, analysed and interpreted the data, and wrote the manuscript; J. D. oversaw the conceptualisation of the study, interpretation of the results and writing of the manuscript; A. B. contributed to the statistical analyses; A. D. contributed to the conceptualisation of the study. J.-L. V. contributed to the literature search and the statistical analyses. All authors contributed to and approved the final draft of the paper.

None of the authors has any conflicts of interest to declare.

\section{References}

1. Prentice RL (2010) Dietary assessment of nutritional epidemiology research reports. Am J Clin Nutr 102, 583-585.

2. Prentice RL, Huang Y, Kuller LH, et al. (2011) Biomarker-calibrated energy and protein consumption and cardiovascular disease risk among postmenopausal women. Epidemiology 22, 170-179.

3. Prentice RL, Shaw PA, Bingham SA, et al. (2009) Biomarkercalibrated energy and protein consumption and increased cancer risk among postmenopausal women. Am J Epidemiol 169, 977-989.

4. Trabulsi J \& Schoeller DA (2001) Evaluation of dietary assessment instruments against doubly labeled water, a biomarker of habitual intake. Am J Physiol Endocrinol Metab 281, E891-E899.

5. Bingham SA, Luben R, Welch A, et al. (2003) Are imprecise methods obscuring a relation between fat and breast cancer? Lancet 362, 212-214.

6. Goldberg GR, Black AE, Jebb SA, et al. (1991) Critical evaluation of energy intake data using fundamental principles of energy physiology: 1 . Derivation of cut-off limits to identify under-recording. Eur J Clin Nutr 45, 569-581.
7. Black AE, Goldberg GR, Jebb SA, et al. (1991) Critical evaluation of energy intake data using fundamental principles of energy physiology: 2. Evaluating the results of published surveys. Eur J Clin Nutr 45, 583-599.

8. Black AE (2000) The sensitivity and specificity of the Goldberg cut-off for EI:BMR for identifying diet reports of poor validity. Eur J Clin Nutr 54, 395-404.

9. Black AE (2000) Critical evaluation of energy intake using the Goldberg cut-off for energy intake: basal metabolic rate. A practical guide to its calculation, use and limitations. Int J Obes 24, 1119-1130.

10. European Food Safety Agency (2009) Guidance of EFSA General Principles for the Collection of National Food Consumption Data in the View of a Pan-European Dietary Survey. EFSA J 7, 1435.

11. Schofield WB (1985) Predicting basal metabolic rate, new standards and review of previous work. Human Nutr Clin Nutr 39, Suppl. 1, 5-41.

12. Owen OE, Kavle E \& Owen RS (1986) A reappraisal of caloric requirements in healthy women. Am J Clin Nutr $\mathbf{4 4}$, $1-19$.

13. Owen OE, Holup JL, D'Alessio DA, et al. (1987) A reappraisal of the caloric requirements of men. Am J Clin Nutr $\mathbf{4 6}$, $875-885$.

14. Mifflin MD, St Jeor ST, Hill LA, et al. (1990) A new predictive equation for resting energy expenditure in healthy individuals. Am J Clin Nutr 51, 241-247.

15. Müller MJ, Bosy-Westphal A, Klaus S, et al. (2004) World Health Organization equations have shortcomings for predicting resting energy expenditure in persons from a modern, affluent population: generation of a new reference standard from a retrospective analysis of a German database of resting energy expenditure. Am J Clin Nutr 80, 1379-1390.

16. Henry CJK (2005) Basal metabolic rate studies in humans: measurement and development of new equations. Public Health Nutr 8, 1133-1152.

17. Lafay L, Basdevant A, Charles MA, et al. (1997) Determinants and nature of dietary underreporting in a free-living population: the Fleurbaix Laventie Ville Santé (FLVS) study. Int J Obes 21, 567-573.

18. Macdiarmid J \& Blundell J (1998) Assessing dietary intake: who, what and why under-reporting. Nutr Res Rev 11, $231-253$.

19. Gnardellis C, Boulou C \& Trichopoulou A (1998) Magnitude, determinants and impact of under-reporting of energy intake in a cohort study in Greece. Public Health Nutr 1, 131-137.

20. Lafay L, Mennen A, Basdevant A, et al. (2000) Does energy intake underreporting involves all kinds of food or only specific food items? Results from the Fleurbaix Laventie Ville Santé (FLVS) study. Int J Obes 24, 15000-11507.

21. Johansson G, Wikam A, Ahrén AM, et al. (2001) Underreporting of energy intake in 24-hour recalls related to gender, age, weight status, day of interview, educational level, reported food intake, smoking habits and area of living. Public Health Nutr 4, 919-927.

22. Black AE \& Cole TJ (2001) Biased over- and under-reporting is characteristic of individuals whether over time by different assessment methods. J Am Diet Assoc 101, 70-80.

23. Livingstone MBE \& Black AE (2003) Markers of the validity of reported energy intake. J Nutr 133, 895S-920S.

24. Sallé A, Ryan M \& Ritz P (2006) Under-reporting of food intake in obese diabetic and non diabetic patients. Diabetes Care 29, 2726-2727.

25. Yannakoulia M, Panagiotakos DB, Pitsavos C, et al. (2007) Low energy reporting related to lifestyle, clinical, and 
psychosocial factors in a randomly selected population sample of Greek adults: the ATTICA study. J Am Coll Nutr 26, 327-333

26. Rasmussen LB, Matthiessen J, Biltoft-Jensen A, et al. (2007) Characteristics of misreporters of dietary intake and physical activity. Public Health Nutr 10, 230-237.

27. Poslusna K, Ruprich J, De Vries JHM, et al. (2009) Misreporting of energy and micronutrient intake estimated by food records and 24 hour recalls, control and adjustment methods in practice. Br J Nutr 101, S73-S85.

28. Lutomski JE, Van Den Broeck J, Harrington J, et al. (2010) Sociodemographic, lifestyle, mental health and dietary factors associated with direction of misreporting of energy intake. Public Health Nutr 14, 532-541.

29. Lioret S, Touvier M, Balin M, et al. (2011) Characteristics of energy under-reporting in children and adolescents. $\mathrm{Br} J$ Nutr 105, 1671-1680.

30. Mendez MA, Wynter S, Wilks R, et al. (2004) Under- and overreporting of energy is related to obesity lifestyle factors and food group intakes in Jamaican adults. Public Health Nutr 7, 9-19.

31. Mendez MA, Popkin BM, Buckland G, et al. (2011) Alternative methods of accounting for underreporting and overreporting when measuring dietary intake-obesity relations. Am J Epidemiol 173, 448-458.

32. Meng X, Kerr DA \& Zhu K (2013) Under-reporting of energy intake in elderly Australian women is associated with a higher body mass index. J Nutr Health Aging 17, 112-118.

33. Schoch AH \& Raynor HA (2012) Social desirability, not dietary restraint, is related to accuracy of reported intake of a laboratory meal in females during 24-hour recall. Eat Behav 13, 78-81.

34. Harrison GG, Galal OM, Ibrahim N, et al. (2000) Underreporting of food intake by dietary recall is not universal: a comparison of data from Egyptian and American women. J Nutr 130, 2049-2054.

35. Wyndels K, Dallongeville J, Simon C, et al. (2011) Regional factors interact with educational and income tax levels to influence food intake in France. Eur J Clin Nutr 65 , $1067-1075$.

36. Dietary Survey Unit - Nutritional Epidemiology (OCA-EN) (2009) Report of the French INCA2 Dietary Survey (étude Individuelle Nationale des Consommations Alimentaires 2) 2006/2007. Maisons-Alfort: AFSSA.

37. Lioret S, Dubuisson C, Dufour A, et al. (2010) Trends in food intake in French children from 1999 to 2007: results from the INCA (étude Individuelle nationale des Consommations Alimentaires) dietary surveys. Br J Nutr 103, 585-601.

38. Dufour A, Lafay L \& Volatier JL (2008) La mesure des consommations alimentaires par l'enquête INCA2. Méthodes de sondage (Measure of Food Consumption Based on the INCAZ Survey. Sampling Methods), pp. 132-138. Paris: Dunod.

39. World Health Organization (1997) Obesity: Preventing and Managing the Global Epidemic. Report of a WHO Consultation. WHO Technical Report Series no. 894. Geneva: WHO.

40. Hercberg S, Deheeger M \& Preziosi P (1994) SU-VI-MAX. Portions Alimentaires. (Photo Manual for Quantity Estimation). Paris: Poly Technica.

41. Favier J, Ireland J, Toque C, et al. (1995) Répertoire général des aliments (General Directory of Foods). Paris: Tec\& Doc.

42. Ireland J, du Chaffaut L \& Oseredczuk M, et al. (2010) French Food Composition Table, version 2008.1. http://www.afssa. fr, French Food Safety Agency, AFSSA (accessed June 2010).

43. Lee PH, Macfarlane DJ, Lam TH, et al. (2011) Validity of the International Physical Activity Questionnaire Short Form (IPAQ-SF): a systematic review. J Epidemiol 8, 1-11.
44. Food and Agriculture Organization (2001) Human Energy Requirements. Report of a Join FAO/WHO/UNU Expert Consultation. Food and Nutrition Technical Report Series no. 1. Rome: FAO.

45. INSEE (2007) Comptabilité nationale, base 2000. Annuaire statistique de la France (National Accounts, 2000 Base. Statistical Directory of France). Paris: INSEE.

46. Subar AF, Kipnis V, Troiano RP, et al. (2003) Using intake biomarkers to evaluate the extent of dietary misreporting in large sample adults: the OPEN study. Am J Epidemiol 158, $1-13$.

47. Ferrari P, Slimani N, Ciampi A, et al. (2002) Evaluation of under- and overreporting of energy intake in 24-hour diet recalls in the European Prospective Investigation into Cancer and Nutrition (EPIC). Public Health Nutr 5, $1329-1345$.

48. Rennie KL \& Coward Ajenn SA (2007) Estimating underreporting of energy intake in dietary surveys using an individualized method. Br J Nutr 97, 1169-1176.

49. Becker W, Foley S, Shelley E, et al. (1999) Energy underreporting in Swedish and Irish dietary surveys: implications for food-based dietary guidelines. Br J Nutr 81, 8127-8131.

50. Murakami K, Sasaki S, Okubo H, et al. (2011) Characteristics of under- and over-reporters of energy intake among young Japanese women. J Nutr Sci Vitaminol 58, 253-262.

51. Freisling H, van Bakel MME, Biessy C, et al. (2012) Dietary reporting errors on $24 \mathrm{~h}$ recalls and dietary questionnaires are associated with BMI across six European countries as evaluated with recovery biomarkers for protein and potassium intake. Br J Nutr 107, 910-920.

52. Dlugosz A \& Wadolowska L (2011) Comparison of socioeconomic status and body composition of dietary energy under-reporting and non-under-reporting youth. Pol J Food Nutr Sci 61, 279-288.

53. Koebnick C, Wagner K, Thielecke F, et al. (2005) An easy-touse semiquantitative food record validated for energy intake by using doubly labeled water technique. Eur J Clin Nutr 59, 989-995.

54. Luhrmann PM, Herbert BM \& Neuhauser-Berthold M (2001) Underreporting of energy intake in an elderly German population. Nutrition 17, 912-916.

55. Tomoyasu NJ, Toth MJ \& Poehlman ET (2000) Misreporting of total energy intake in older African Americans. Int $J$ Obes Relat Disord 24, 20-26.

56. European Food Safety Authority (2013) Scientific opinion on dietary reference values for energy. EFSA J 11, 3005.

57. Livingstone MBE, Prentice AM, Strain JJ, et al. (1990) Accuracy of weighed dietary records in studies of diet and health. Br Med J 300, 708-712.

58. Herbert RH, Clemow L, Pbert L, et al. (1995) Social desirability bias in dietary self-report may compromise the validity of dietary intake measures. Int J Epidemiol 24, 389-398.

59. Herbert RH, Yunsheng M, Clemow L, et al. (1997) Gender differences in social desirability and social approval bias in dietary self-report. Am J Epidemiol 146, 1046-1055.

60. French Agency for Food, Environmental and Occupational Health, Safety (2010) Evaluation des risqué liés aux pratiques alimentaires d'amaigrissement. Rapport d'expertise collective Editions scientifiques (Assessment of risks connected to the food practices of loss of weight). Report of collective expertise. Scientific editions. http://www. anses.fr/Documents/NUT2009sa0099Ra.pdf (accessed June 2013).

61. Sichert-Hellert W, Kersting M \& Schoch G (1998) Underreporting of energy intake in 1 to 18 year old German children and adolescents. Z Ernabrungswiss 37, 248-251. 
62. De Vries JHM, de Groot LCPGM \& van Staveren WA (2009) Dietary assessment in elderly people: experiences gained from studies in The Netherlands. Eur J Clin Nutr 63, S69-S74

63. Millen AE, Tooze JA, Subar AF, et al. (2009) Differences between food group reports of low-energy reporters and non-low-energy reporters on a food frequency questionnaire. J Am Diet Assoc 109, 1194-1203.

64. Summerbell CD (1996) Differences in reported macronutrient composition of the diet in overweight and lean individuals depend on validity of reported energy intakes. Proc Nutr Soc 55, 232A.

65. Tooze JA, Subar AF, Thompson E, et al. (2004) Psychosocial predictors of energy underreporting in a large doubly labeled water study. Am J Clin Nutr 79, 795-804.

66. Schleicher RL, McCoy LF, Powers CD, et al. (2013) Serum concentrations of an aflatoxin-albumin adduct in the National Health and Nutrition Examination Survey (NHANES) 1999-2000. Clin Chim Acta 423, 46-50.

67. Alshaarawy O, Zhu M, Ducatman A, et al. (2013) Polycyclic aromatic hydrocarbon biomarkers and serum markers of inflammation. A positive association that is more evident in men. Environ Res 126, 98-104.

68. Ferrari P, Freisling H, Duell EJ, et al. (2013) Challenges in estimating the validity of dietary acrylamide measurements. Eur J Nutr 52, 1503-1512.

69. Tinker LF, Sarto GE, Howard BV, et al. (2011) Biomarkercalibrated dietary energy and protein intake associations with diabetes risk among postmenopausal women from the Women's Health Initiative. Am J Clin Nutr 94, 1600-1606.

70. Slimani N, Bingham S, Runswick S, et al. (2003) Group level validation of protein intakes estimated by 24 -hour diet recall and dietary questionnaires against 24-h urinary nitrogen in the European Prospective Investigation into Cancer and Nutrition (EPIC) calibration study. Cancer Epidemiol Biomarkers Prev 12, 784-795.

71. Briefel RR, Sempos CT, McDowell MA, et al. (1997) Dietary methods research in the third National Health and Nutrition Examination Survey: under-reporting of energy intake. $A m \mathrm{~J}$ Clin Nutr 65, 1203S-1209S.

72. Whybrow S \& Kirk TR (1997) Nutrient intakes and snacking frequency in female students. J Hum Nutr Diet 10, 237-244.

73. SACN (2011) Dietary reference values for energy. http:// www.sacn.gov.uk (accessed August 2013).

74. Bratteby LE, Sandhagen B, Fan H, et al. (1998) Total energy expenditure and physical activity as assessed by the doubly labeled water method in Swedish adolescents in whom energy intake was underestimated by 7 -d diet records. $A m$ J Clin Nutr 67, 905-911.

75. Ekelund U, Aman J, Yngve A, et al. (2002) Physical activity but not energy expenditure is reduced in obese adolescents: a case-control study. Am J Clin Nutr 76, 935-941.

76. Shetty P, Henry CJK, Black AE, et al. (1996) Energy requirements of adults: an update on basal metabolic rates (BMRs) and physical activity levels (PALs). Eur J Clin Nutr 50, S11-S23.

77. Hill A \& Roberts J (1998) Body mass index: a comparison between self-reported and measured height and weight. $J$ Public Health Med 20, 206-210.

78. Villanueva EV (2001) The validity of self-reported weight in adults: a population based cross-sectional study. BMC Public Health 1, 1-10.

79. Craig BM \& Adams AK (2009) Accuracy of body mass index categories based on self-reported height and weight among women in the United States. Matern Child Health J 13, 489-496. 